\title{
Senile Cardiac Amyloidosis: An Undervalued Cause of Heart Failure.
}

\author{
Toni Anne Alvarez de Venecia \\ Albert Einstein Medical Center \\ Scott Blumhof \\ Albert Einstein Medical Center \\ Daniel Ukpong \\ Albert Einstein Medical Center \\ Marvin Lu \\ Albert Einstein Medical Center \\ Claudia Nieves \\ Albert Einstein Medical Center \\ Follow this and additional works at: https://jdc.jefferson.edu/cardiologyfp \\ Part of the Cardiology Commons

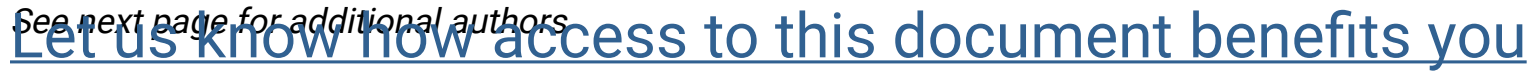

\section{Recommended Citation}

Alvarez de Venecia, Toni Anne; Blumhof, Scott; Ukpong, Daniel; Lu, Marvin; Nieves, Claudia; and Figueredo, M.D., Vincent M., "Senile Cardiac Amyloidosis: An Undervalued Cause of Heart Failure." (2014). Division of Cardiology Faculty Papers. Paper 55.

https://jdc.jefferson.edu/cardiologyfp/55

This Article is brought to you for free and open access by the Jefferson Digital Commons. The Jefferson Digital Commons is a service of Thomas Jefferson University's Center for Teaching and Learning (CTL). The Commons is a showcase for Jefferson books and journals, peer-reviewed scholarly publications, unique historical collections from the University archives, and teaching tools. The Jefferson Digital Commons allows researchers and interested readers anywhere in the world to learn about and keep up to date with Jefferson scholarship. This article has been accepted for inclusion in Division of Cardiology Faculty Papers by an authorized administrator of the Jefferson Digital Commons. For more information, please contact: JeffersonDigitalCommons@jefferson.edu. 


\section{Authors}

Toni Anne Alvarez de Venecia; Scott Blumhof; Daniel Ukpong; Marvin Lu; Claudia Nieves; and Vincent M. Figueredo, M.D. 


\section{Senile Cardiac Amyloidosis: An Undervalued Cause of Heart Failure}

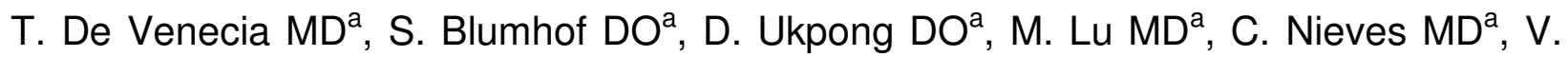
Figueredo $M D^{b, c}$

(a) Department of Internal Medicine, Albert Einstein Medical Center, Philadelphia, PA

(b) Einstein Institute for Heart and Vascular Health, Albert Einstein Medical Center, Philadelphia, PA

(c) Sidney Kimmel Medical College of Thomas Jefferson University

Conflict of Interest: The authors have no conflicts of interest to report

Funding: None; All authors had access to the data and a role in writing the manuscript

Running Title: Senile Cardiac Amyloidosis and Heart Failure

Keywords: Senile Cardiac Amyloidosis, Heart Failure

Corresponding Author: Toni Anne De Venecia M.D.

Internal Medicine Resident, Albert Einstein Medical Cener

5501 Old York Road, $3^{\text {rd }}$ Floor Klein Building

Department Internal of Medicine

Philadelphia, PA 19141

$215-456-6500$

detonian@einstein.edu 
To the Editor

Despite recurrent hospitalizations for heart failure exacerbations the underlying etiology can be missed. Senile amyloidosis is a disease prevalent in the elderly African American population. Senile amyloidosis is underdiagnosed as a cause of heart failure due to its occurrence with more common comorbidities such as long standing systemic hypertension. It is important to maintain a high index of suspicion for senile amyloidosis in patients such as this case, who presented with multiple exacerbations of heart failure combined with characteristic electrocardiographic and echocardiographic findings.

\section{Clinical Presentation}

This is the case of a 71-year-old African American male with non-ischemic cardiomyopathy presumed secondary to hypertensive heart disease that presented with heart failure symptoms. He had previous hospitalizations for heart failure exacerbations in the past 2 years.

The patient's medical regimen included an angiotensin converting enzyme inhibitor (ACE-I), beta-blocker and a thiazide diuretic. EKG showed low voltage QRS complexes in all leads. The brain natriuretic peptide (BNP) was elevated. Chest $x$-ray revealed bilateral pleural effusions with an enlarged heart. Transthoracic echocardiography revealed marked biventricular hypertrophy, global hypokinesis, severe diastolic dysfunction and dilated atria; suggestive of infiltrative cardiomyopathy (Figure 1). Echocardiogram from 6 months earlier revealed the same findings. Serum and urine protein electrophoresis, serum free light chains and immunoglobulins, and a fat pad biopsy were unremarkable. Bone marrow biopsy demonstrated hypercellular marrow and polyclonal plasmacytosis which ruled out plasma cell dyscrasias.

\section{Discussion}

There are significant findings in this case that leads to the correct but previously missed diagnosis. The ECG showed low voltage limb leads. The echocardiogram revealed 
biventricular hypertrophy, global hypokinesis, dilated atria, and a restrictive pattern suggestive of infiltrative cardiomyopathy. This combination of EKG and echocardiographic findings should raise clinical suspicion for amyloidosis, which is the most common prototype of infiltrative heart disease with increased wall thickness.[1] The endomyocardial biopsy showed amyloid deposition, specifically wild type transthyretrein protein deposition.

Amyloidosis is an infiltrative multisystem disease with the severity of specific organ involvement (including the heart) dependent on the precursor protein.[2] There are different types, but the case presented is that of the senile cardiac amyloidosis. Senile cardiac amyloidosis almost always affects men in their seventies as a slow progressive disease with only cardiac involvement.[3] The first signs of senile cardiac amyloidosis are usually leg swelling or shortness of breath, both due to congestive heart failure.[4]

Therapy for senile cardiac amyloidosis is, at present, purely symptomatic relief. Medications for heart failure, such as ACE-I, beta-blocker and diuretics are still the mainstay for treatment. Patients with senile cardiac amyloidosis however, not uncommonly progress to complete heart block, and permanent pacing becomes necessary.[5] Prompt referral to advanced heart failure physicians may improve quality of life and reduce readmissions due to heart failure exacerbations in such patients. 
References:

1. Seward, James MD, Versoza, Grace MD. Infiltrative Cardiovascular Diseases Cardiomyopathies That Look Alike. J Am Coll Cardiol. 2010;55(17):1769-1779. doi:10.1016/j.jacc.2009.12.040

2. Falk, Rodney MD. Cardiac Amyloidosis, A treatable disease often overlooked. Circulation. 2011; 124: 1079-1085.

3. Connors LH, Prokaeva T, Lim A, Theberge R, Falk RH, Doros G, Berg A, Costello CE, O'Hara C, Seldin DC, Skinner M. Cardiac

amyloidosis in African Americans: comparison of clinical and laboratory features of transthyretin $\mathrm{V} 122 \mathrm{I}$ amyloidosis and immunoglobulin light chain amyloidosis. Am Heart J. 2009;158:607-614.

4. Ng B, Connors LH, Davidoff R, Skinner M, Falk RH. Senile systemic amyloidosis presenting with heart failure: a comparison with light chain-associated amyloidosis. Arch Intern Med. 2005;165:1425-142 magnetic resonance in cardiac amyloidosis. Circulation. 2005;111:186-193.

5. Coelho T, Maia L, Martins da Silva A, Waddington Cruz M, Plante'-Bordeneuve V, Lozeron P, Suhr OB, Campistol J, Conceic ,ao I, Schmidt H, Trigo P, Packman J,Grogan DR. A comprehensive evaluation ofthe disease-modifying effects of tafamidis in patients with transthyretin type familial amyloid polyneuropathy. Presented at: American Academy of Neurology Annual Meeting; April 2011; Honolulu, HI

Figure Legend 
Figure 1. Parasternal long axis view on transthoracic echocardiogram demonstrating biventricular hypertrophy and left atrial enlargement

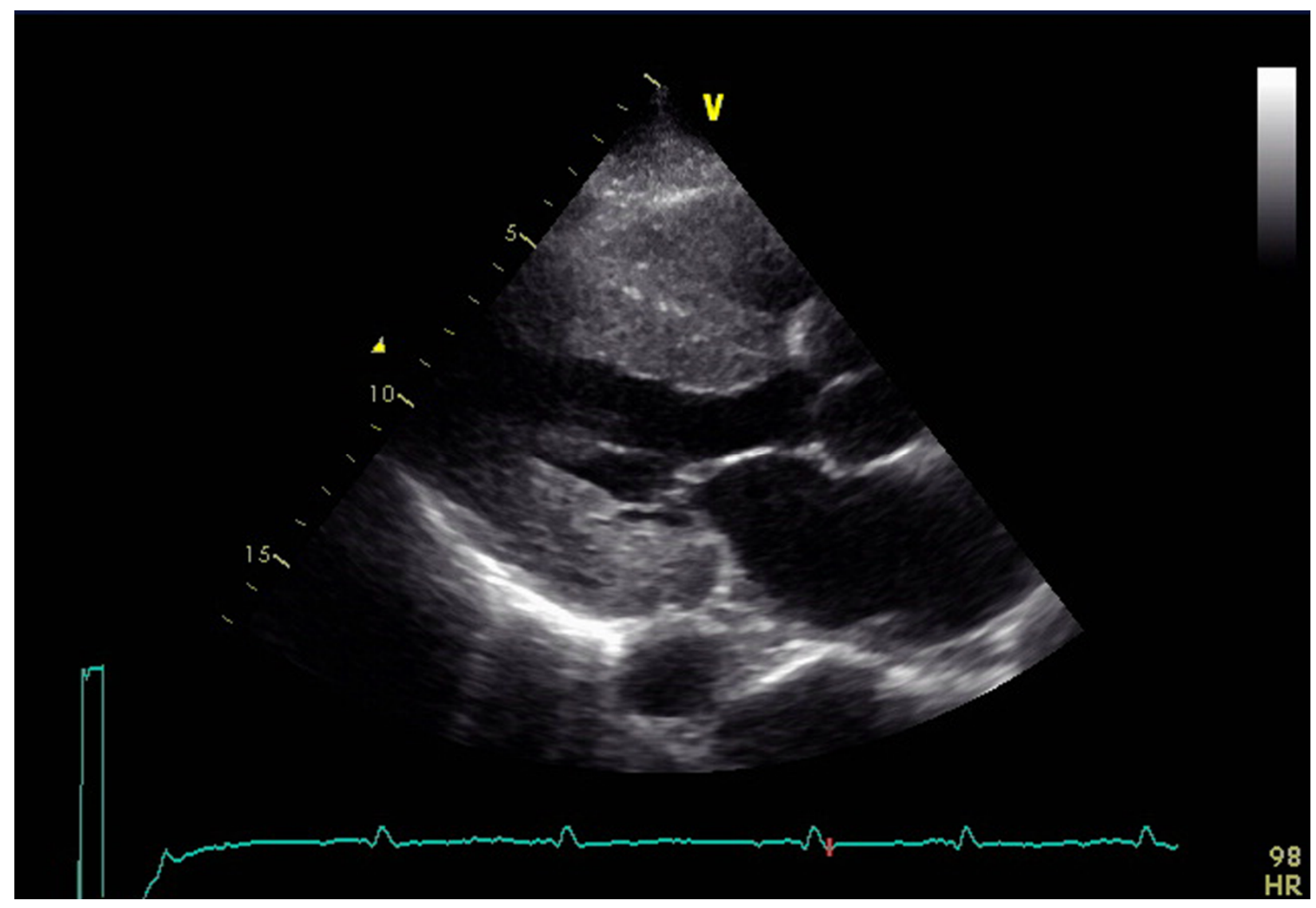

